\section{Realising early recognition of arthritis in times of increased telemedicine: the value of patient- reported swollen joints}

Early diagnosis and management of patients with inflammatory arthritis (IA) are critical to improve long-term patient outcomes. Assessment of joint swelling at joint examination is the reference of IA identification; early access clinics are constructed to promote this early recognition. Due to the COVID-19 pandemic, the face-to-face capacity of such services is severely reduced. ${ }^{1}$ This raises the concern of a major step backward after the important progress that has been made in the past 15 years. ${ }^{1}$ Telemedicine has recently become rapidly implemented. Although probably a valuable alternative in the management of established rheumatoid arthritis (RA), there is also the fear that this might cause delay in the speed of diagnosis. ${ }^{2}$ A symptom that evidently raises suspicion for IA during remote evaluation is the presence of patient-reported swelling. This symptom is also included in triage tools. ${ }^{34}$

The accuracy of patient-reported swelling in comparison with joint examination has been extensively evaluated in established RA. Heterogeneous results are reported; correlation coefficients were higher when patient scored their swelling on mannequins ( $\rho: 0.31-0.67)$ than when determined with questions. ${ }^{5}$ Hypothetically, the accuracy of patient-reported joint swelling for first recognition of IA is different than for flare detection in patients with established RA. To promote evidence-based care in the era of telemedicine, we determined the accuracy of patient-reported joint swelling for actual presence of IA in persons suspected of IA by general practitioners (GPs).

Data from two Dutch Early Arthritis Recognition Clinics were studied. These are screening clinics (1.5 lines setting) where GPs send patients in case of doubt on IA. At this clinic, patients were asked to mark the presence of swollen joints on a mannequin with 52 joints (42 joints were used for this analysis, see online supplemental text/figure S1). Subsequently, an experienced rheumatologist performed joint examination (see online supplemental text). Clinically apparent IA of $\geq 1$ joint was the reference to calculate sensitivity, specificity, positive and negative likelihood ratios (LR + and LR - ) and positive and negative predictive value (PPV and NPV) on patient level. Pearson correlation coefficients ( $\rho)$ were determined. Predictive values depend on the prevalence of a disease in a population. Because the prevalence of IA in a 1.5 lines setting will differ from a primary care setting, posttest probabilities of IA were estimated for two lower prior-test probabilities as example, namely $20 \%$ (estimated probability in patients GPs believe IA is likely) and 2\% (prior-test probability with less preselection by GPs), using likelihood ratios and nomograms (online supplemental figures S2 and S3).

A total of 1637 consecutive patients were studied. Patient characteristics are presented supplementary (online supplemental table S1). Median symptom duration was 13 weeks. Seventy-six per cent of patients marked $\geq 1$ swollen joint at the mannequin. Forty-one per cent of patients had $\geq 1$ swollen joint at examination by rheumatologists. $\rho$ was 0.20 (patient level) to 0.26 (joint level).

The sensitivity of patient-reported joint swelling was high, $87 \%$, indicating that the majority of patients with IA had marked swelling on the mannequin. However, the specificity was $31 \%$, indicating that $69 \%$ of persons without IA had also done so (figure $1 \mathrm{~A})$. The $\mathrm{LR}+$ was 1.25 ; the $\mathrm{LR}-0.43$. The PPV
A

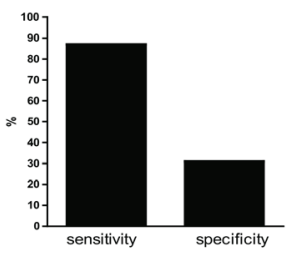

Probability on clinical arthritis if patients indicate $\geq 1$ swollen joints (PPV)
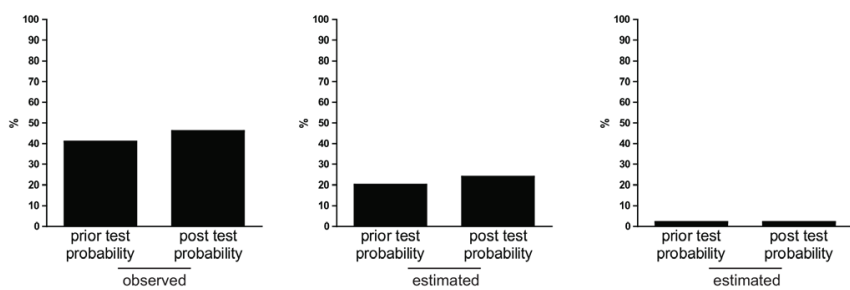

C Probability on absence of clinical arthritis if patients indicate no swollen joints (NPV)
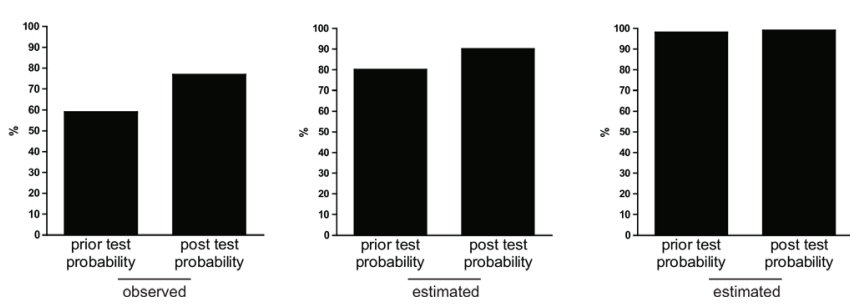

Figure 1 Test characteristics of patient-reported joint swelling $(A)$ and predictive values ( $B$ and $C$ ), demonstrating the limited value of patientreported joint swelling for detection of IA in three settings with different prior probabilities. (A) Sensitivity and specificity of patient-reported swollen joints with IA (joint swelling at physical examination as golden standard). (B) Prior probability on having IA of $41 \%$ (observed), $20 \%$ (estimated) and $2 \%$ (estimated) with corresponding post-test probabilities on having IA, if patients indicate to have $\geq 1$ swollen joints (PPV). (C) Prior-test probability of not having IA 59\% (observed), 80\% (estimated) and $98 \%$ (estimated) with the corresponding post-test probability on not having IA, if patients indicate no swollen joints (NPV). $I A$, inflammatory arthritis; NPV, negative predictive value; PPV, positive predictive value.

was $46 \%$, and the NPV was $77 \%$ (figure $1 \mathrm{~B}, \mathrm{C}$ ). Thus, the PPV increased hardly (from $41 \%$ to $46 \%$ ), and the NPV somewhat increased (from 59\% to $77 \%$ ). Also in settings with prior-test probabilities of $20 \%$ and 2\%, estimated PPVs and NPVs hardly increased (figure 1B,C).

Thus, patient-reported joint swelling had little value in distinguishing patients with and without IA, for different prior-test probabilities. Correlations identified in this population were lower than known for established RA. When evaluating $\geq 1$ selfreported swollen and tender joints, similar results were obtained (online supplemental table S2). Together this suggests that evaluation of patient-reported swelling is less valuable for early detection of IA than for flare detection in established RA. ${ }^{56}$

Thanks to the current pandemic, telemedicine has accelerated and will continue to grow in upcoming years. ${ }^{12}$ The challenge is to continue to work in an evidence-based manner. Although inaccurate when assessed alone, patient-reported swelling may be helpful when combined with other characteristics (either clinical characteristics, such as published previously, and/or laboratory characteristics). ${ }^{3} 478$ Other innovative tools, for example, imaging modalities that do not 
require human-to-human contact, may also contribute to early identification of IA in a ' $1.5 \mathrm{~m}$ society' with limited access to rheumatologists.

Cleo Rogier $\odot,{ }^{1}$ Bastiaan T van Dijk $\odot{ }^{2}$ Elisabeth Brouwer, ${ }^{3}$ Pascal H P de Jong, ${ }^{1}$ Annette H M van der Helm-van Mil $\odot^{1,2}$

'Department of Rheumatology, Erasmus Medical Center, Rotterdam, Zuid-Holland, The Netherlands

${ }^{2}$ Department of Rheumatology, Leiden University Medical Center, Leiden, ZuidHolland, The Netherlands

${ }^{3}$ Department of Rheumatology and Clinical Immunology, UMCG, Groningen, The Netherlands

Correspondence to Dr Cleo Rogier, Rheumatology, Erasmus Medical Center, Rotterdam 3015GD, The Netherlands; c.rogier@erasmusmc.nl

\section{Handling editor Josef S Smolen}

Contributors All authors contributed to the conception or design of the study. BvD, EB and AvdH-vM contributed to the data acquisition. CR, BvD, PHPdJ and AvdH-vM performed data analyses. CR, PHPdJ and AvdH-vM wrote the first version of the manuscript. All authors critically reviewed the paper and approved the final manuscript for publication.

Funding This study was funded by Dutch Arthritis Foundation.

Competing interests None declared.

Patient consent for publication Not required.

Ethics approval The Leiden University Medical Centre medical ethical committee approved the study (P16.163) and granted a waiver for obtaining written informed consent in accordance with Dutch law on medical research due to data collection being limited to data acquired as part of usual care.

Provenance and peer review Not commissioned; externally peer reviewed.

Supplemental material This content has been supplied by the author(s) It has not been vetted by BMJ Publishing Group Limited (BMJ) and may not have been peer-reviewed. Any opinions or recommendations discussed are solely those of the author(s) and are not endorsed by BMJ. BMJ disclaims all liability and responsibility arising from any reliance placed on the content. Where the content includes any translated material, BMJ does not warrant the accuracy and reliability of the translations (including but not limited to local regulations, clinical guidelines, terminology, drug names and drug dosages), and is not responsible for any error and/or omissions arising from translation and adaptation or otherwise.$$
\text { (2) }
$$$$
\text { OPEN ACCESS }
$$

Open access This is an open access article distributed in accordance with the Creative Commons Attribution 4.0 Unported (CC BY 4.0) license, which permits others to copy, redistribute, remix, transform and build upon this work for any purpose, provided the original work is properly cited, a link to the licence is given and indication of whether changes were made. See: https://creativecommons.org/ licenses/by/4.0/.

(C) Author(s) (or their employer(s)) 2021. Re-use permitted under CC BY. Published by BMJ.

- Additional material is published online only. To view, please visit the journal online (http://dx.doi.org/10.1136/annrheumdis-2020-219513).

\section{Check for updates}

To cite Rogier C, van Dijk BT, Brouwer E, et al. Ann Rheum Dis 2021;80:668-669.

Received 13 November 2020

Revised 21 December 2020

Accepted 22 December 2020

Published Online First 7 January 2021

Ann Rheum Dis 2021;80:668-669. doi:10.1136/annrheumdis-2020-219513

ORCID iDs

Cleo Rogier http://orcid.org/0000-0003-3783-7042

Bastiaan T van Dijk http://orcid.org/0000-0002-5161-6791

Annette H M van der Helm-van Mil http://orcid.org/0000-0001-8572-1437

\section{REFERENCES}

1 Caporali R, Favalli EG. Managing patients with rheumatic conditions during the covid-19 pandemic. BMJ 2020:369:m1633.

2 Lauper K, Bijlsma JWJ, Burmester GR. Trajectories of COVID-19 information in the Annals of the rheumatic diseases: the first months of the pandemic. Ann Rheum Dis 2021;80:annrheumdis-2020-219217.

3 Bell MJ, Tavares R, Guillemin F, et al. Development of a self-administered early inflammatory arthritis detection tool. BMC Musculoskelet Disord 2010;11:50.

4 Ten Brinck RM, van Dijk BT, van Steenbergen HW, et al. Development and validation of a clinical rule for recognition of early inflammatory arthritis. BMJ Open 2019;8:e023552.

5 Barton JL, Criswell LA, Kaiser R, et al. Systematic review and metaanalysis of patient self-report versus trained assessor joint counts in rheumatoid arthritis. J Rheumatol 2009:36:2635-41.

6 Radner H, Grisar J, Smolen IS, et al. Value of self-performed joint counts in rheumatoid arthritis patients near remission. Arthritis Res Ther 2012;14:R61.

7 Barbour JA, Binding J, Bridges $M$, et al. Evaluation of a screening tool for inflammatory joint disease. Ann Rheum Dis 2003;62:187-8.

8 Emery P, Breedveld FC, Dougados M, et al. Early referral recommendation for newly diagnosed rheumatoid arthritis: evidence based development of a clinical guide. Ann Rheum Dis 2002:61:290-7. 